\title{
IMPACT OF TRANS-BOUNDARY POLLUTION (PM-2.5) ON THE AIR QUALITY OF DHAKA CITY IN BANGLADESH
}

\author{
Musfekur R. Dihan, S. M. Abu Nayeem and M.A.A. Shoukat Choudhury* \\ Department of Chemical Engineering, Bangladesh University of Engineering and Technology, \\ Dhaka-1000, Bangladesh
}

\begin{abstract}
Clean air is a basic need of human beings for its existence. In recent years, air pollution in city areas, especially in Dhaka and Chittagong, has become a significant threat to health and well-being. Dhaka is found to suffer a high level of pollution during the dry season, which is from November to April, especially for Particulate Matter, PM2.5, concentration. From December to February this situation is found to be the worst crossing the WHO guidelines and National Ambient Air Quality Standard. Bangladesh is surrounded by countries with the fastest-growing economy like India and China who use coal-burning technologies for different purposes such as producing power and running mills. They release the lion's share of the air pollutants in South Asia and these pollutants easily get transported to neighboring countries. This is known as transboundary pollution. This study investigates the contribution of transboundary transportation of PM-2.5 in the air quality of Dhaka city. Ninety-Six hours of air mass back trajectories were computed using the Hybrid Single-Particle Lagrangian Integrated Trajectory (HYSPLIT-4) model and those trajectories were grouped into 6 clusters. Probability calculation showed that Dhaka city air has a higher probability of getting pollutants from long-range sources when air masses traveled through North, West, and North-West direction covering the North Eastern and North-Western territories of India, Nepal, and its neighboring areas. Concentration Weighted Trajectory (CWT) analysis also supported that those areas could be potential sources of getting unwanted PM-2.5 on our atmosphere.
\end{abstract}

Keywords: Trans-Boundary Pollution, PM-2.5, Back Trajectory Analysis, CWT analysis, Bangladesh.

\section{Introduction}

Air pollution is commonly defined as the presence of contaminants or pollutant substances in the air that interfere with human health or welfare or produce other harmful environmental effects[1]. It has become a significant threat to health and the environment in recent years [2][3]. Rapid development, urbanization, motorization, fossil fuel burning, and power generation are considered to be the core reasons behind massive atmospheric quality degradation [4][5][6]. As posing serious adverse effects on health such as various cardiovascular diseases, respiratory problems, lung cancer [4][7], and effects on climate change [7][3][5] air pollution is drawing more attention nowadays. Particulate Matter (PM), Ozone $\left(\mathrm{O}_{3}\right)$, Nitrogen dioxide $\left(\mathrm{NO}_{2}\right)$ and Sulphur dioxide $\left(\mathrm{SO}_{2}\right)$ are recognized as common pollutants [7][2][8]. Among those, airborne Particulate Matter (PM-10, PM-2.5) has drawn much attention because of their long lifetime, particle size, serious damages to health in long time exposure [4], and ability to travel a long distance crossing one country border to others[3][7]. Like other countries in Asia, Bangladesh is suffering a high level of air pollution especially in the dry season (October to April). PM-2.5 concentration often exceeds the standard level set by WHO [2] and Bangladesh National Ambient Air Quality Standard
[9] in the dry season [10][11][12]. Brick kilns emission, fossil fuel combustion, re-suspended dust from roads are reported as the main sources behind PM pollution in the Dhaka city air in Bangladesh [11][13]. Countries like China and India emit a high level of PM pollutants in the air as they mostly rely on coal-based power plants for energy production [6][14][15]. These countries are leveled as highly polluted countries and there are speculations that they contribute a high level of transboundary air pollution (TAP) to the neighboring countries[15]. Because of wind direction in the dry season (North, North-westerly wind mainly dominate which travel over the polluted region of India and then enter Bangladesh) and the long-range traveling ability of PM-2.5, the transboundary effect contributes significantly to PM concentration in Bangladesh [16]. A few studies [12][17][18] revealed that the air of Dhaka city is getting some unwanted PM-2.5 from other countries through long-range air mass traveling. This study aims to find out the probable contribution of long-range transportation of PM-2.5 on Dhaka's atmosphere during the time interval from November-2019 to April-2020. Cluster analysis using HYSPLIT-4 indicates the wind directions for this period and probability calculation finds out the probability of carrying pollutants with air masses from a specific direction. CWT method conducted in this study provides support to find out 
transboundary source strength from moderate to high. This study is conducted taking only Dhaka's PM-2.5 concentration data for six months, so results obtained from this study can't be generalized for the whole year or the whole country. As there are very few available studies in Bangladesh on this phenomenon, we believe our attempt to identify and quantify the TAP on Dhaka's atmosphere would motivate more researchers to investigate this phenomena.

\section{Methods and Materials}

\subsection{Sampling Site Location}

Bangladesh is located in the eastern part of South Asia. Its capital, Dhaka, is surrounded by rivers and has a flat topology. Hourly data of PM-2.5 concentration was taken from the archived data stored by the AirNow project of the United States of America[19]. The sample point is chosen as the US Embassy, Dhaka having latitude $23.7968^{\circ}$ north and longitude $90.4219^{\circ}$ east. A map of the sampling

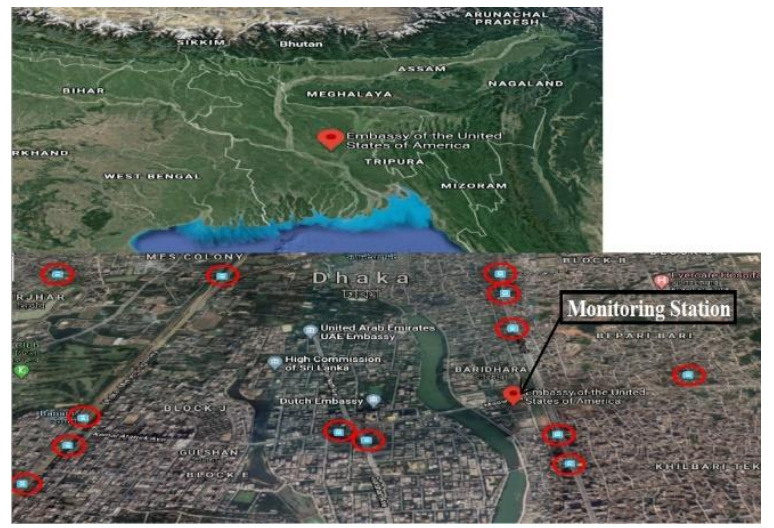

Figure 1: Location of the study area. Red circles denoting the bus stoppage near the sampling site.

location is given in Figure 1. The site is located in a residential area in Dhaka city having many bus stations and roads. The Bus stations are red marked on the map. Being situated in one of the most populated cities in the world, the air quality monitoring station might receive a remarkable amount of PM concentration from vehicle emissions and resuspension of dust particles from roads.

\subsection{Local Meteorology}

Bangladesh is situated in the South Asian region having adequate rainfall, the comparatively high temperature varying from $24^{\circ}-35^{\circ}$, and high humidity. Typically, a year can be divided into four-season, Premonsoon (March-May), Monsoon (June-September), Post-monsoon (November-April), winter (DecemberFebruary)[20][21]. The highest humidity was found in July and the lowest in December [11].
According to [12], meteorology was divided into mainly two seasons: Dry (November- April) and Wet (May-October). The dry season experiences low cloud coverage, weak sun, little rainfall, and mainly north, north-westerly wind.

\subsection{Trajectory and Cluster Analysis}

Hybrid Single-Particle Lagrangian Integrated Model (HYSPLIT) is one of the most extensively used atmospheric dispersion and transport models for calculating air mass back trajectories. It uses both the Lagrangian and Eulerian methods to estimate pathways of air mass parcel originating from an initial location and the pollutant air concentration respectfully. It is considered a very useful model to determine the origin of the air masses and the pollutants' sources[22][23]. Ninety-six-hour air mass backward trajectories arriving at the US Embassy station, Dhaka during the whole dry season (November 2019 to April 2020) were calculated using HYSPLIT-4 downloading global reanalysis data from the archive of the National Oceanic Atmospheric Administration (NOAA)[24]. The GDAS1 (Global Data Assimilation System, horizontal resolution $1^{\circ}$ ) data file containing wind speed, wind direction, temperature, cloud coverage, and relative humidity was used for the backward trajectory calculation. The starting point was kept 200 meters above ground level and trajectories were calculated at 6 hours intervals each day $(00,6,12,18$ UTC). All the trajectories that were calculated were clustered into 6 groups according to their 'angle distance matrix', a measure of the similarity between two back trajectory points in terms of their angle from the starting location of the back trajectories, on the above software [23][24].

\subsection{Probability Calculation of PM Association}

The probability of each cluster carrying a specific amount of PM-2.5 particles was calculated following the procedure described in [15]. Hourly data of PM2.5 concentration were assigned with respective trajectories arriving at the station at that time. Probability was calculated according to

$$
P(c x)=\frac{N(c x)}{N(c)}
$$

here, $P(c x)=$ Probability of trajectories under cluster $C$ to carry PM-2.5 concentration greater then x; $N(c x)=$ Number of trajectories under cluster $C$ associated with PM-2.5 concentration greater then $\mathrm{x}$. $N(c)=$ Number of total trajectories under cluster $C$.

When setting correlation with particular trajectories of a cluster for carrying long-range pollutants, some conditions like the level of PM-2.5 concentration associated with that cluster and local sources on the way of air trajectories were taken into account. 


\subsection{Concentration Weighted Trajectory $(C W T)$}

The Concentration Weighted Trajectory (CWT) for locating potential long-range sources with their strength that might affect the atmospheric condition was calculated using TrajStat, a GIS-based software[25]. CWT is a receptor model that is widely used for identifying long-range pollution sources by assigning every grid cell a weighted concentration by averaging sample concentration that has associated trajectories crossing that grid cell[26, 27].

\subsection{Statistical Analysis}

Statistical Package for Social Science (SPSS) was used for statistical analysis of concentration data. Data were tabulated, scrutinized, and organized using excel. Then a descriptive analysis of data was carried out using the statistical test at a significance level of $95 \%$ $(P<0.05)$.

\section{Results and Discussion}

\subsection{Characteristics of PM-2.5 Concentration}

Figure-2 shows the monthly pattern of PM-2.5 pollution from November 2019 to April 2020. It has been observed that the city experiences a high level of pollution during this period (Figure 2a). December to February is found to be more polluted compared to other months. During these months, $24 \mathrm{hr}$. average
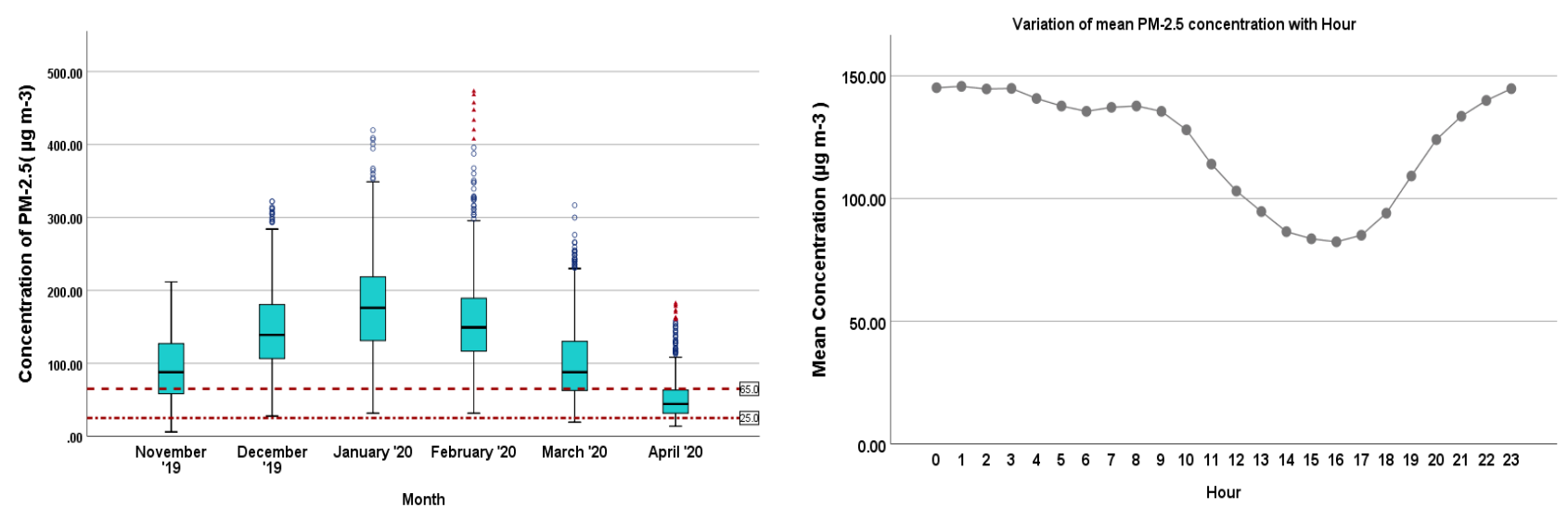

Figure 2: Pattern of PM-2.5 concentration. (a) Box-Whisker plot showing the variation of PM-2.5 concentration with months. Horizontal lines on each box denote median values. Two reference lines showing BNAAQS and WHO standard respectfully. (b) Summary plot of concentration by the hour.

Table 1:

Descriptive statistics of PM 2.5 concentration $\left(\mu \mathrm{gm}^{-3}\right)$ during dry months.

\begin{tabular}{|c|c|c|c|c|c|c|}
\hline & & Mean & Median & Maximum & Minimum & Standard Deviation \\
\hline \multirow{5}{*}{ Months } & November '19 & 91.97 & 87.90 & 211.60 & 6.00 & 44.80 \\
\hline & December '19 & 146.04 & 138.90 & 322.10 & 27.60 & 56.91 \\
\hline & February '20 & 159.90 & 149.30 & 472.90 & 31.60 & 64.84 \\
\hline & March '20 & 101.17 & 87.80 & 316.70 & 19.40 & 51.88 \\
\hline & April '20 & 52.24 & 44.30 & 182.30 & 13.70 & 29.88 \\
\hline
\end{tabular}

values of PM 2.5 pollution exceeded the values set National Ambient Air Quality Standard of Bangladesh $\left(65 \mu \mathrm{g} \mathrm{m}^{-3}\right)$ as shown in Figure $2 \mathrm{a}$. The box plot in Figure $2 \mathrm{a}$ shows the whisker box with 25 to 75 percentiles, the outliers are shown as circles and the extreme points (triangles) are the points that exceed 1.5 of interquartile length. The worst affected month

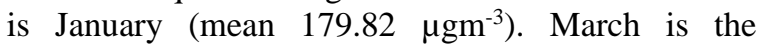
transition month between highly polluted and comparatively low polluted months, associated with several outliers and extremes but pollution level decreased a little bit relative to January. April is found to be in a moderate state relative to other months having most of the days under standard level (mean $52.24 \mu \mathrm{gm}^{-3}$ ). Comparatively low standard deviation $\left(29.88 \mu \mathrm{gm}^{-3}\right)$ of April denotes that the low PM-2.5 pollution was quite stable and had low variation. Figure 2(b) shows the PM-2.5 concentration profile over a $24 \mathrm{hr}$. period. As shown in the figure, PM-2.5 concentration sharply increases at night time and high concentration prevails in the morning. Then concentration fell continuously until evening. Office and school hours start in the morning, so vehicular emission might lead to an increase in PM-2.5 concentration. The descriptive statistics (Mean, Median, Standard deviation, Maximum, Minimum) of PM-2.5 concentration over the entire dry season are given in Table-1.

Hour 


\subsection{Cluster Analysis}

Ninety-six hours back trajectories at six hours' intervals in a day throughout the entire dry seasonending at the monitoring station (The US Embassy, Dhaka) can be clustered into 6 groups (Figure 3) and they are named C-1 to C- 6 . Their characteristics and direction can be found in Table- 3 .

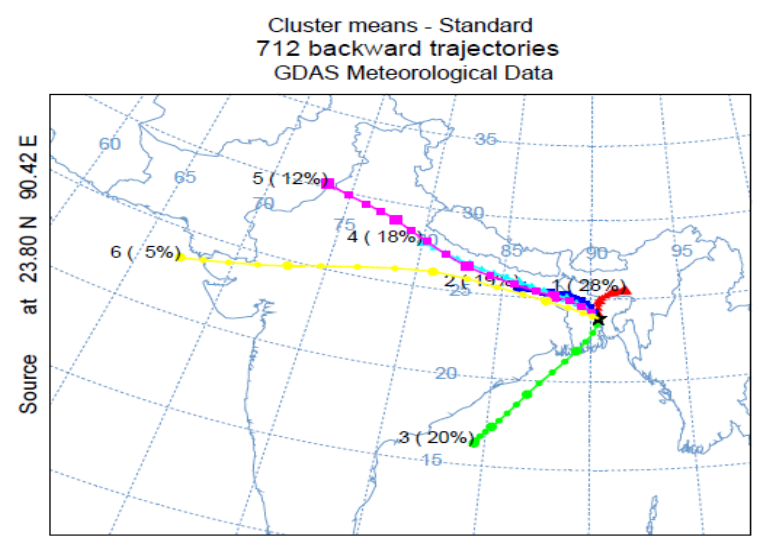

Figure 3: Six mean clusters of all backward trajectories ending at the station.

Most trajectories under C-4, C-5, and C-6 correspond to the western part of Bangladesh bringing air masses from the Indian region (Rajasthan, Lucknow, Punjab, New Delhi, Uttar Pradesh), PakIndia border, Middle East (Iran, Afghanistan). Air from those directions traveled a long distance before entering Dhaka air. Trajectories that traveled short distances are grouped into $\mathrm{C}-1$ and $\mathrm{C}-2$ having a mixed pattern and mostly coming from the north and western part borders of the country. Trajectories of C-3 brought air masses from the south and they are mainly marine air.

\subsection{Probability and PM-2.5 Association with Cluster}

Wind patterns and their domination on different months of the dry season can be expressed in Figures 4 and 5. It can tell the mean amount of pollutants they have carried to the monitoring station. Air masses traveling from north and north-east, north-west (C-1 and C-2) dominated mostly in November and December and these trajectories carried most of the pollutants during these months. On the other hand, trajectories originating from southern parts, mainly from the Bay of Bengal, started in March and were found mostly in April (almost $86 \%$ of the trajectories of that month are from C-3).

The monitoring station received air from almost all the directions (except $\mathrm{C}-3$ direction) from January to March and the C-1, C-2, C-4 and C-5 carried the most - amount of PM-2.5 to the monitoring station during these months. From Figure-5, trajectories under C-4 and C-5 carried a higher amount of PM-2.5 from January to March relative to their contribution in other months. C- 6 has only 5\% of trajectories and has been more active since January.
Table 2 shows that C-2, C-4, C-5 were the clusters that had a higher probability of injecting a high level of fine particles on the monitoring station. The station had an almost $81 \%$ of probability of getting PM-2.5 concentration of greater than $100 \mu \mathrm{g} \mathrm{m}^{-3}$ when the air was received from the $\mathrm{C}-4$ direction. The rank of clusters with a higher probability of carrying pollutants from long-range sources is given in Table-3 considering their PM-2.5 association, pathway, directions and entrance towards stations. Trajectories

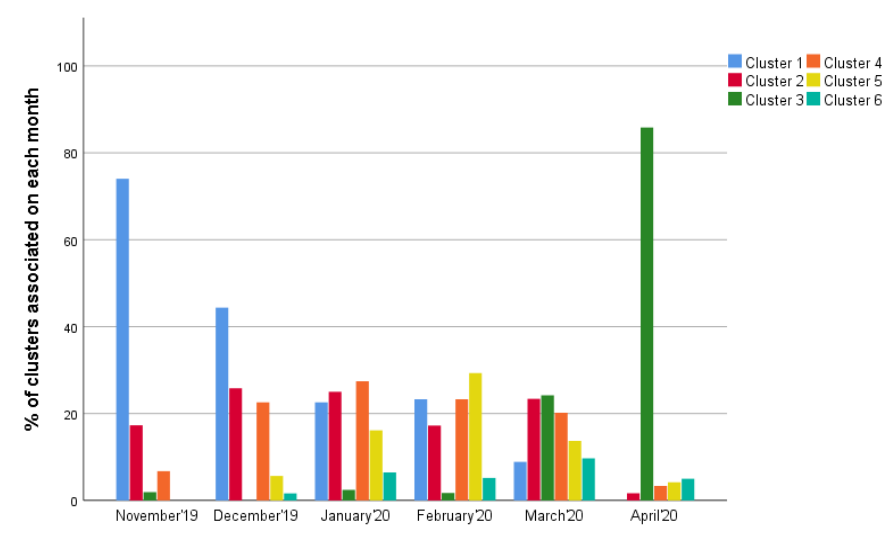

Figure 4: Clustered bar plot showing the percentage of trajectories of the clusters associated with different months.

under the C-3 cluster came mainly from the southern part, south-east direction, Marine air, and associated with a comparatively low level of pollution. Although trajectories under C-1 and C-2 associated with a high level of pollution but they mainly originated from the Northern, North-West and North-Eastern part having zig-zag pathways within our country's border traveling short distances and were more likely to be exposed to local sources namely road dust, brick kilns and local industries. So, C-1, C-2, C-3 were less likely to carry pollutants from distant sources. Air masses

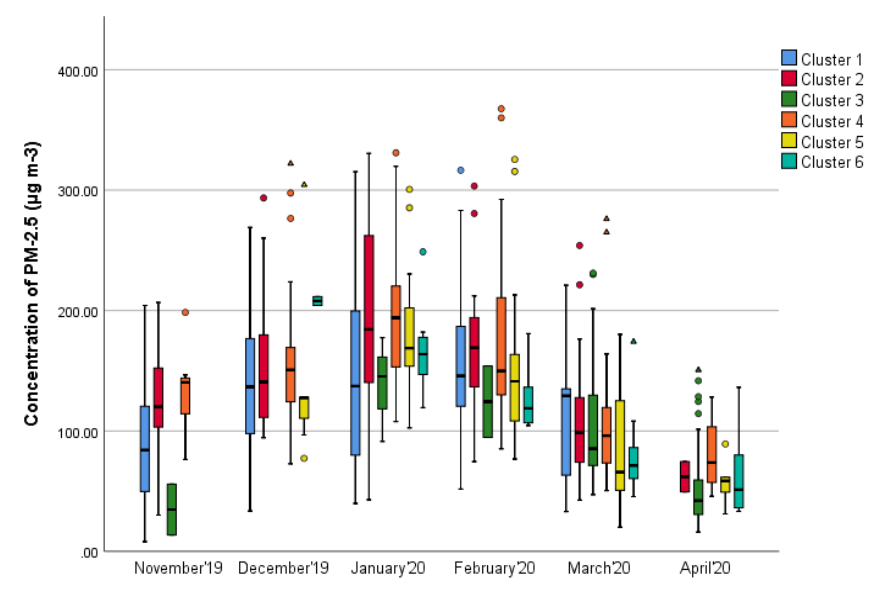

Figure 5: Box-Whisker plot showing the variation of mean concentration on each month grouped by respective clusters. Boxes cover 25-75 percentile and whiskers are 1.5 times of Inter-Quartile length. Circles and triangles showing outliers and extremes respectfully.

within 96 hours and mostly dominated from January to March, the months with higher pollution, came from 
western, north-west regions reported to emit a high level of pollutants on air namely India, Indian-Pak territories, Middle east. As having a low number of trajectories, C- 6 can be credited less responsible relative to $\mathrm{C}-4$ and $\mathrm{C}-5$ to be a long-range pollutant carrier route. So, ultimately trajectories under C-4, C5 are found to be prime air masses that can be associated with C-4, C-5, C-6 traveled longer distances suspected for contributing to transboundary air pollution.

Table 2:

Probability (\%) of carrying PM-2.5 concentration $\left(\mu \mathrm{g} \mathrm{m}^{-3}\right)$ associated with six clusters.

\begin{tabular}{|c|c|c|c|c|c|c|}
\hline \multirow[b]{2}{*}{ Cluster No } & \multirow[b]{2}{*}{$\begin{array}{c}\text { Total } \\
\text { Trajectories }\end{array}$} & \multicolumn{5}{|c|}{ Probability $(\%)$ of getting PM-2.5 concentration $\left(\mu \mathrm{g} / \mathrm{m}^{3}\right)$ greater than } \\
\hline & & $>50$ & $>100$ & $>150$ & $>200$ & $>250$ \\
\hline C-1 & 198 & 85.9 & 59.1 & 27.3 & 9.1 & 4.0 \\
\hline C-2 & 132 & 95.5 & 77.3 & 41.7 & 18.2 & 11.4 \\
\hline C-3 & 140 & 52.1 & 14.3 & 6.4 & 2.9 & 0.0 \\
\hline C-4 & 125 & 99.2 & 80.8 & 47.2 & 24.0 & 12.8 \\
\hline C-5 & 83 & 92.8 & 72.3 & 41.0 & 12.0 & 6.0 \\
\hline C-6 & 34 & 88.2 & 55.9 & 26.5 & 8.8 & 0.0 \\
\hline
\end{tabular}

Table 3:

The path and direction of six clusters and their relative ranking as long-range pollutant carriers. Rank is denoted by numerical values, 1 is for very high pollution association and 6 is for very low.

\begin{tabular}{|c|c|c|c|}
\hline \multirow[b]{2}{*}{ Cluster } & \multirow[b]{2}{*}{ Path, Direction of Trajectories } & \multicolumn{2}{|c|}{ Rank in Terms of } \\
\hline & & Pollution Association & $\begin{array}{l}\text { Long Range } \\
\text { Pollutant Carrier }\end{array}$ \\
\hline C-1 & North, North-east, concentrated within countries border and shorter pathway & Moderate (4) & Low \\
\hline $\mathrm{C}-2$ & $\begin{array}{l}\text { Mostly from North-westerly, traveled shorter distance, some from the west, Indian } \\
\text { border region, and Nepal. }\end{array}$ & High (2) & Moderate \\
\hline $\mathrm{C}-3$ & $\begin{array}{l}\text { Marine air. Started from south, south-west, and entered the station from the south. } \\
\text { A few from the eastern Indian region }\end{array}$ & Low (6) & Low \\
\hline C-4 & $\begin{array}{l}\text { Almost everyone from North-westerly direction passing over Lucknow, Uttar } \\
\text { Pradesh and New Delhi and some from the Indo-Nepal border }\end{array}$ & Very High (1) & High \\
\hline C-5 & $\begin{array}{l}\text { Traveled a long way starting from the Indo-Pak border and bringing air from } \\
\text { Lahore, Panjab, Rajasthan, New Delhi }\end{array}$ & High (3) & High \\
\hline C-6 & $\begin{array}{l}\text { Most of them had long flights originating from the Middle East (Iran, } \\
\text { Afghanistan), some from the western part of India and the Indian Ocean. }\end{array}$ & Moderate (5) & Moderate \\
\hline
\end{tabular}

\subsection{CWT analysis}

Figure 6 shows gridded concentration weighted trajectories (CWT) with the ability to identify the potential source region for PM-2.5 pollutants from where air mass can carry a high level of pollutants to the station.

For this reason, the concentration of PM-2.5 with respective trajectories are assigned. Yellow to deep red color suggests that the cells are associated with a higher level of PM-2.5 concentration than the green, blue, white and ash color cells. From figure- 6 , the cells in the southern direction are in light color suggesting that those regions are associated with a low level of pollution.

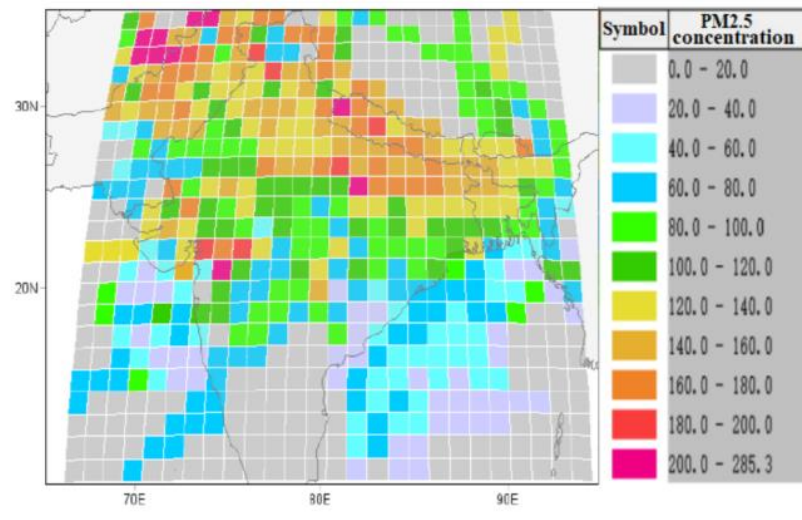

Figure 6: CWT approach, gridded back trajectory concentration showing mean PM-2.5 concentration. Relative strength of area are shown in colored grids. PM- 2.5 concentration is expressed in $\mu \mathrm{g} / \mathrm{m}^{3}$. 
So, it is evident that trajectories under the C-3 cluster have low probability as it carried mainly air masses from the Bay of Bangel and associated with low concentration. The transboundary effect from the eastern zone can be excluded as there are high mountains and the cells in that direction have light colors. Cells with higher probability and a higher level of concentration were found from the north, northwest, west, north-eastern direction. So this suggests that the region bordering BangladeshEastern Indian territories, North India, Area bordering Nepal, India-Pakistan border- could be the possible sources that could carry pollutants. The spotted areas are following the pathways of C-2, C4, C-5, C-6 clusters (table-3). As discussed earlier, the trajectories under $\mathrm{C}-2$ traveled a comparatively short distance and have the probability of engaging with local sources and C- 6 has a low number of trajectories $(5 \%)$. Although they have a higher level of PM-2.5 association, they can be classified as clusters that have a moderate impact on long-range pollutants carrier.

\section{Conclusion}

Particulate Matter (PM) pollution has become extreme over recent years which could be because of increasing local pollution as well as due to the transboundary pollution effect. This study attempted to investigate a different approach to understand the patterns of PM pollution and the probable contribution of long-range sources. The following conclusions can be drawn from this study:

- The city experienced a high level of PM pollution in the dry season (November 2019 to April 2020). The month of January and February were found to be the worst months in terms of PM concentration exceeding both the National Ambient Air Quality Standard and WHO standard.

- Ninety-six hours back trajectory on HYSPILT-4 identified that the monitoring station at the US embassy of Dhaka received PM polluted winds mostly from the north and northwest direction. Southerly air dominated in March and April has low pollution level. Air masses traveled from north, north-west, and west direction have a higher probability of getting pollutants.

- CWT analysis along with the results of cluster analysis showed that Bangladesh might be a victim of getting pollutants from North Indian territories, the India-Nepal border, India-Pakistan border and the Eastern Indian region bordering Bangladesh.

This study suggests that further research is needed for identifying the long-range sources from which our country is getting unexpected transboundary pollutants and thereby take proper steps in a complex regional aspect.

\section{Acknowledgments}

The authors are grateful to the US Embassy for supplying the concentration data of PM-2.5.

\section{References}

[1] United States Environmental Protection Agency (US EPA) https://www.epa.gov/environmental-topics/airtopics (accessed Jul 5, 2021).

[2] WHO. WHO Air Quality Guidelines for Particulate Matter, Ozone, Nitrogen Dioxide and Sulfur Dioxide.

[3] Intergovernmental Panel on Climate Change. Climate Change 2007; Cambridge University Press: Cambridge, 2007; Vol. 9780521880. https://doi.org/10.1017/CBO9780511546013.

[4] WHO. The World Health Organization Report 2002: Reducing Risks, Promoting Healthy Life; 2002.

[5] Seinfeld, JH, P. S. Atmospheric Chemistry and Physics:From Air Pollution to Climate Change, Third Edit.; 2018.

[6] Wang, S.; Hao, J. Air Quality Management in China: Issues, Challenges, and Options. J. Environ. Sci., 2012, 24 (1), 2-13. https://doi.org/10.1016/S10010742(11)60724-9.

[7] EPA. Air Quality Index: A Guide to Air Quality and Your Health; 2014.

[8] Vallero, D. A. The Changing Face of Air Pollution. In Funfamentals of Air Pollution; Elsevier Ltd: UK, 1978; pp 3-47.

[9] Department of Environment (DoE). Air Quality and Vehicular Emission Standards; Dhaka.

[10] Clean Air and Sustainable Environment (CASE) project, D. Monthy Progress Reports.

[11] Salam, A.; Hossain, T.; Siddique, M. N. A.; Alam, A. M. S. Characteristics of Atmospheric Trace Gases, Particulate Matter, and Heavy Metal Pollution in Dhaka, Bangladesh. Air Qual. Atmos. Heal., 2008, 1 (2), 101-109. https://doi.org/10.1007/s11869-0080017-8.

[12] Rana, M. M.; Sulaiman, N.; Sivertsen, B.; Khan, M. F.; Nasreen, S. Trends in Atmospheric Particulate Matter in Dhaka, Bangladesh, and the Vicinity. Environ. Sci. Pollut. Res., 2016, 23 (17), 1739317403. https://doi.org/10.1007/s11356-016-6950-4.

[13] Begum, B. A.; Biswas, S. K.; Markwitz, A.; Hopke, P. K. Identification of Sources of Fine and Coarse Particulate Matter in Dhaka, Bangladesh. Aerosol Air Qual. Res., 2010, 10 (4), 345-353. https://doi.org/10.4209/aaqr.2009.12.0082.

[14] Abas, N.; Saleem, M. S.; Kalair, E.; Khan, N. Cooperative Control of Regional Transboundary Air Pollutants. Environ. Syst. Res., 2019, 8 (1). https://doi.org/10.1186/s40068-019-0138-0.

[15] Du, X.; Jin, X.; Zucker, N.; Kennedy, R.; Urpelainen, J. Transboundary Air Pollution from Coal-Fired Power Generation. J. Environ. Manage., 2020, 270 (November 2019), 110862. 
https://doi.org/10.1016/j.jenvman.2020.110862.

[16] Lawrence, M. G.; Lelieveld, J. Atmospheric Pollutant Outflow from Southern Asia: A Review. Atmos. Chem. Phys., 2010, 10 (22), 11017-11096. https://doi.org/10.5194/acp-10-11017-2010.

[17] Rana, M. M.; Mahmud, M.; Khan, M. H.; Sivertsen, B.; Sulaiman, N. Investigating Incursion of Transboundary Pollution into the Atmosphere of Dhaka, Bangladesh. Adv. Meteorol., 2016, 2016, 111. https://doi.org/10.1155/2016/8318453.

[18] Saadat, A.; Rahman, M.; Hasan.SM; Alam, A. T Ravelling and Source Point Identification of Some Transboundary Air Pollutants by Trajectory Analysis in Sathkhira, Bangladesh. Can. Chem. Trans., 2013, 1 (1), 56-65. https://doi.org/10.13179/ canchemtrans. 2013.01.01.0011.

[19] Air-Now.Air Quality Data https:// bd.usembassy. gov/embassy/air-quality-data/ (accessed Apr 5, 2020).

[20] Salam, A.; Bauer, H.; Kassin, K.; Mohammad Ullah, S.; Puxbaum, H. Aerosol Chemical Characteristics of a Mega-City in Southeast Asia (Dhaka-Bangladesh). Atmos. Environ., 2003, 37 (18), 2517-2528. https://doi.org/10.1016/S1352-2310(03)00135-3.

[21] BEGUM, B. Investigation of Sources of Atmospheric Aerosol at Urban and Semi-Urban Areas in Bangladesh. Atmos. Environ., 2004, 38 (19),30253038. https:// doi.org /10.1016/ j.atmosenv. 2004.02.042.
[22] Stein, A. F.; Draxler, R. R.; Rolph, G. D.; Stunder, B. J. B.; Cohen, M. D.; Ngan, F. NOAA's HYSPLIT Atmospheric Transport and Dispersion Modeling System. Bull. Am. Meteorol. Soc., 2015, 96 (12), 2059-2077. https://doi.org/10.1175/BAMS-D-1400110.1 .

[23] Draxler, R.; Stunder, B.; Rolph, G.; Stein, A.; Taylor, A. HYSPLIT User's Guide Version 5; 2020.

[24] Draxler, R. R.; G. D. Rolph. HYSPLIT-4 (Hybrid Single-Particle Lagrangian Integrated Trajectory) Model. NOAA, Air Resources Laboratory,: USA 2003.

[25] Wang, Y. Q.; Zhang, X. Y.; Draxler, R. R. TrajStat: GIS-Based Software That Uses Various Trajectory Statistical Analysis Methods to Identify Potential Sources from Long-Term Air Pollution Measurement Data. Environ. Model. Softw., 2009, 24 (8), 938-939. https://doi.org/10.1016/j.envsoft.2009.01.004.

[26] Seibert, P.; Kromp-Kolb, H.; Baltensperger, U.; D, J.; M, S.; A, K.; H, P. Trajectory Analysis of Aerosol Measurements at High Alpine Sites. In Transport and Transformation of Pollutants in the Troposphere,; Academic Publishing, 1994; pp 689-693.

[27] Stohl, A. Trajectory Statistics-A New Method to Establish Source-Receptor Relationships of Air Pollutants and Its Application to the Transport of Particulate Sulfate in Europe. Atmos. Environ., 1996,30(4),579-587. https://doi.org/10.1016/13522310(95)00314-2. 